\title{
Hepatic encephalopathy in patients in Lviv (Ukraine)
}

\author{
Herbert Djiambou-Nganjeu \\ Division of Hepato-gastroenterology of Internal Medicine Department at Lviv Regional Clinical Hospital, Danylo \\ Halytsky Lviv National Medical University, Ukraine
}

\section{ABSTRACT}

Background and Objectives: Hepatic encephalopathy (HE) research has long been impeded by the vague definition of this disabling complication of liver failure. This article provides an overview of the etiology and impact of HE on neuromuscular functions as well as its role in the development of infections and anemia. Materials and Methods: This was a descriptive study conducted in 36 patients with HE. Close monitoring of these patients was done by checking on several parameters. Results: The etiological distribution: alcohol $(67 \%)$, hepatitis $C$ virus (HCV; $17 \%), \mathrm{HCV}$ and alcohol (8\%), hepatitis B virus (HBV; $3 \%), \mathrm{HBV}$ and alcohol (3\%), HBV and HCV (6\%), and cryptogenic (3\%). The laboratory results indicated an elevation of De Ritis level in $69 \%$ of cases and in $92 \%$ of total bilirubin values. The Halstead-Reitan (H-R) test score with regards to gender indicated that more than half of the patients had a score of 2 , while only few cases received the scores 3 and 4 . The frequency of $H-R$ score with regards to Child-Pugh score showed the significant preponderance of Child-Pugh score of 7-9 (B): 58.3\% compared to others groups of results, and these results indicated patients' poor prognosis. Conclusion: Findings showed the preponderance of female patients towards developing HE and the poor survival rate of patients older than 65 years. Alcohol and hepatitis $C$ were the main causes associated with the development of HE. The neurological assessment marked the preponderance of Child-Pugh grades $B$ and $C$ and also the prevalence in female patients with neuropsychological disabilities through the assessment of $\mathrm{H}-\mathrm{R}$ test.

Key words: hepatic encephalopathy, alcoholic and viral liver cirrhosis, Halstead-Reitan, Child-Pugh score, coagulopathy

\section{INTRODUCTION}

Hepatic encephalopathy (HE) represents a syndrome with a broad spectrum of neuropsychiatric abnormalities, which is characterized by the common presentation of liver cirrhosis after the ruling out of other brain diseases as possible differential diagnosis. ${ }^{[1-3]} \mathrm{HE}$ is noticeable in patients with portosystemic shunting or alteration of liver function, usually presenting through the following symptomatology that begins with coupling of psychomotor lowering and alteration, followed by the advancement to personality changes, depression, lethargy, impaired intellectual ability, and so on in end-stage coma (with or without response to stimuli) and later death in severe cases. ${ }^{[4]}$ The neuropsychological peculiarity can be revealed by the use of psychometric tests, for instance, neuropsychological tests such as Halstead-Reitan (H-R) score and ChildPugh score or other psychometric tests. ${ }^{[8-10]}$ There is no gold standard test to diagnose HE due to the personal peculiarities of each case. That is why physicians mostly rely on their personal experiences, equipment availability, and clinical findings in order to diagnose this syndrome. ${ }^{[2,1]}$

The aim of our study was to determine the distribution and determinants of $\mathrm{HE}$ through the examination of etiologies and impacts of $\mathrm{HE}$ on neuromuscular functions. In addition, we conducted this metaanalysis to examine whether the evaluation of laboratory data (such as liver, blood, and chemistry values) and neurological and psychometrics tests results could help determine and/or predict the course of the syndrome. We would also evaluate the role of $\mathrm{HE}$ in the development of infections 
and anemia, as well as compare it with the findings of a descriptive study on patients with HE.

\section{MATERIALS AND METHODS}

\section{Study population}

The descriptive study was conducted in the Internal Medicine Department of the Lviv Regional Clinical Hospital, Ukraine. To minimize the bias, all patients were handled with the same questioner and HE confirmed patients were identified and the detailed medical records were taken. By using strict inclusion and exclusion criteria, only patients with confirmed $\mathrm{HE}$ were selected to be part of the report. The study was conducted in 36 patients with confirmed diagnosis liver cirrhosis complicated by HE. Information was collected using structured proforma, and information regarding baseline characteristics of patients were collected [age, body mass index (BMI), gender, $\mathrm{M} / \mathrm{F}$ ratio, drinking periods (D-P), CBC, BMI with regards to $\mathrm{HE}$, etiology, drinking periods (years) related to $\mathrm{HE}, \mathrm{H}-\mathrm{R}$ score with regards to Child-Pugh score, H-R score with regards to genders, and so on]. Next, detailed medical records were received, regarding symptoms of $\mathrm{HE}$, liver disease, and their general physical examinations. Blood laboratory analyses were requested, which included complete blood count, biochemistry, liver enzymes tests, AST/ALT, international normalized ratio (INR), white blood cells (WBC), enzyme-linked immunosorbent assay (ELISA) test, and were analyzed immediately following the sample collection by routine analytical methods. ${ }^{[1-15]} \mathrm{H}-\mathrm{R}$ test and Child-Pugh score were done to patients in order to diagnose $\mathrm{HE}$ and its level of severity. ${ }^{[9,16]}$

\section{Statistical analysis}

A database of tables was created, and sensitivity and specificity calculations were done using the Excel 2016 (Microsoft Office ${ }^{\circledR}$ ) program. The categorical variables were expressed as absolute values and percentages. Measures of central tendency were used for the quantitative variables and measures of frequency for the qualitative variables. The statistical package for social sciences (SPSS, version 16.0, Chicago, IL) was used to enter and analyze the data. ${ }^{[17]}$

\section{Inclusive criteria}

During follow-up, patients with clinical, radiological, histological diagnosis of HE (mean: 1 month, range: 2 months) admitted in the Lviv Regional Clinical Hospital with an indication of hepatocellular dysfunction due to portal hypertension, increased portal diameter $>13 \mathrm{~mm}$ along with encephalopathy, esophageal or gastric varicose veins, and confirmed presence of cirrhosis on biopsy shall be subject to the study. Moreover, patients should present neuropsychological peculiarity such as psychomotor lowering associated with one or more following symptoms that generally begins by the coupling of motor and psychological alteration, followed by the advancement to personality changes (irritability, euphoria): depression, sleepiness, reduced level of consciousness, lethargy, apathy, impaired intellectual ability, tremor, amnesia, and so on.

\section{Ethics}

After receiving permission from the Head of the Department of Internal Medicine, the data collection phase was initiated. Ethical approval was obtained from the Danylo Halytsky Lviv National Medical University/ Lviv Regional Clinical Hospital Ethics Committee, and all the participants were provided a written inform consent in accordance with the Helsinki Declaration. ${ }^{[18]}$ Inform consent was provided after explaining the nature and purpose of the study and assuring patients that participation was voluntary.

\section{Exclusion criteria}

1) Patients who were suffering from any neurological diseases (sclerosis, parkinsonian, intracranial lesions, postseizure encephalopathy, and infections such as encephalitis, meningitis, and intracranial abscess).

2) Patients with malignancy, hemoglobin $(\mathrm{Hb})<8 \mathrm{~g}$ and who had undergone an abdominal paracentesis procedure (within 7 days).

3) Liver diseases associated with pregnancy.

4) Any mental alteration or mental illness making it difficult or impossible to assess the patient.

5) Severe anemia or other hematopoietic disorders that could alter cardiovascular condition.

6) Patients still consuming alcohol at the time of inclusion in the study were also excluded.

7) Patients with drug-induced encephalopathy.

8) Patients suffering from any other conditions causing encephalopathy.

9) Patients with severe complications of liver disease, including hepato-renal syndrome, gastrointestinal bleeding, bacterial infection, spontaneous bacterial peritonitis; patients who undergo treatment with systemic antibiotics, probiotics or norfloxacin for selective gut decontamination, any immunomodulatory or steroid therapy; patients with hepatic or extrahepatic malignancy and any organ failure within the past 30 days. 


\section{RESULTS}

Patients with HE started developing signs and symptoms between the age of 40 and 72 years, with a poor survival rate in elderly patients ( $>65$ years). Demographic representation of patients with $\mathrm{HE}$ was mean age $=48 \pm 12$ years: $28 \%$ of cases in 30-44 years age group, 47\% of cases in 45-59 years age group, and $25 \%$ of cases in $60-74$ years age group; $42 \%$ of cases are male patients and $58 \%$ of cases are female patients. Concerning the etiologies, the study showed that $30 \%$ of cirrhotic cases were of viral origin and $70 \%$ were of non-viral origin (Table 1). Moreover, $8 \%$ cirrhotic patients who had a BMI between 17 and 18.9 developed HE, while HE proportion increased within the BMI ranges of 19-24.9 and 31-34.9. Physician detected the highest occurrence of $\mathrm{HE}$ within patient group with $\mathrm{BMI}$ in the range of 23-24.9, which correspond to onefourth of $\mathrm{HE}$ cases diagnosed. Moreover, the data showed a stabilization of values in patients with BMI in the range of 25-28.9 and 39-42.9, which, respectively, correspond to $11 \%$ and $6 \%$. Patients BMI showed a decline tendency in occurrence of HE cases within BMI groups of 29-30.9, 35-38.9 and 43-44.9. In the contrary, physician detected an elevation of $\mathrm{HE}$ among patients having a BMI in the range of 39-42.9 and 45-46.9 (Figure 1).

HE occurred in more than one-third of cases suffering from acute or chronic alcoholism for less than a year,

\begin{tabular}{lll}
\hline \multicolumn{2}{l}{ Table 1: Etiology distribution of the HE patients } \\
\hline Etiology & $N[M / F$ ratio] & $(\%)$ \\
\hline Alcohol & $24[9 / 15]$ & 67 \\
HCV & $4[1 / 3]$ & 11 \\
HCV \& alcohol & $3[2 / 1]$ & 8 \\
HBV & $1[1 / 0]$ & 3 \\
HBV \& alcohol & $1[1 / 0]$ & 3 \\
HBV \& HCV & $2[0 / 2]$ & 6 \\
Cryptogenic & $1[1 / 0]$ & 3 \\
\hline
\end{tabular}

HBV: hepatitis B virus; $\mathrm{HCV}$ : hepatitis $\mathrm{C}$ virus; $\mathrm{HE}$ : hepatic encephalopathy; $\mathrm{M} / \mathrm{F}$ : male/female; $\mathrm{N}$ : number.

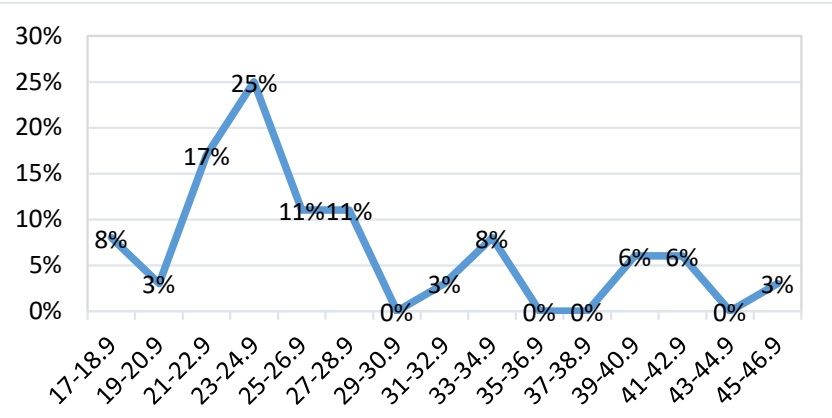

Figure 1: BMI regards HE. BMI: body mass index; HE: hepatic encephalopathy. with an occurrence of $11 \%$ for patients with 2 years of alcoholism and $14 \%$ for those with 10 years of alcoholism. Researcher noticed an elevation and a stabilization in the number of cases for patients with $\mathrm{HE}$ who suffered from more than 20 years of chronic alcoholism. Statistics showed an absence of case for HE for patients with 11-16 and 18-19 years of alcoholism (Figure 2).

Patients with a history of less than a year of acute or chronic alcoholism were more susceptible to develop $\mathrm{HE}$ as a complication of the liver cirrhosis. Another investigation showed that confirmed liver failure induced HE in patients who frequently take alcohol for less than 5 years. Nevertheless, a significant peak of the incidence of encephalopathy among cirrhotic patients suffering from constant alcohol consumption during more than 17 years was also noticed.

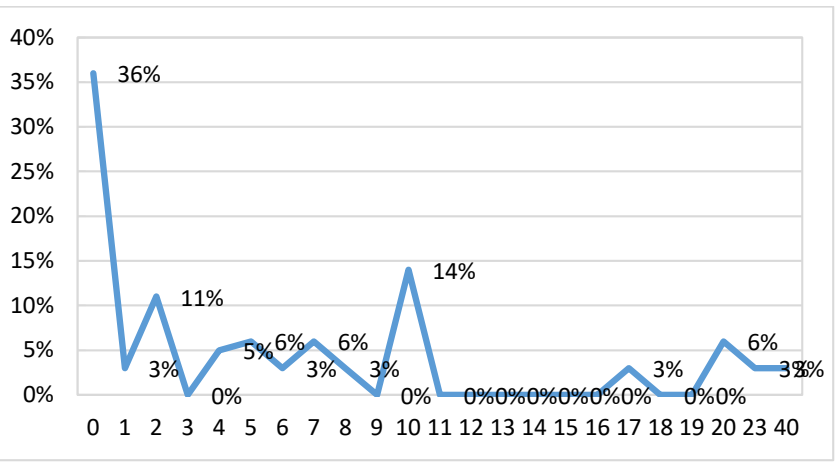

Figure 2: Drinking periods (years) related to hepatic encephalopathy.

A total of $81 \%$ of patients with HE were found with low level of erythrocytes and hemoglobin, which suggested a development of coagulopathy. This was confirmed by an elevated level of INR in $91 \%$ of patients, confirming the first hypothesis. On the full blood count of those patients, we noticed a leukocytosis with shift to the left (Table 2). During the survey, only $36 \%$ of patients were detected with an elevated level of WBC, and it was noticed that $38 \%$ of patients had a significant reduction in WBC level, leaving only $31 \%$ of patients with normal values. Owing to the

\section{Table 2: Laboratory data of patients with HE}

\begin{tabular}{ll}
\hline & Value \\
\hline WBCs $\left(\times 10^{6} / \mathrm{L}\right)$ & $9.4 \pm 3.4$ \\
Male $\mathrm{Hb}(\mathrm{g} / \mathrm{dL})$ & $9.8 \pm 6.9$ \\
Female $\mathrm{Hb}(\mathrm{g} / \mathrm{dL})$ & $8.7+2.5$ \\
Neutrophil & $9.7 \pm 2.9$ \\
Neutrophil Seg. & $90.5 \pm 2.1$ \\
\hline
\end{tabular}

$\mathrm{Hb}$ : hemoglobin; HE: hepatic encephalopathy; SEG: segmented; WBC: white blood cells. 
concomitant presence of acute or chronic infections, the values of WBC were abnormal in $69 \%$ of those patients and also a remarkable increase in the De Ritis score $(>1.75$; $69 \%$ ) and increase in the total bilirubin level in $92 \%$ of cases were detected.

Tests such as H-R test showed that more than half of patients had score 2, while few received scores 1 and 4 (Table 3). Moreover, the association of H-R with regards to Child-Pugh score was more marked in H-R 2 compared to H-R $1 / 3 / 4$ and by Child-Pugh grade B compared to Child-Pugh grade A and C. Moreover, the frequency of $\mathrm{H}-\mathrm{R}$ with regards to Child-Pugh score was more marked in the Child-Pugh grade B (score 7-9) and grade C (score 10-11) (Table 3). Child Pugh grade B had 81\% chance of survival after one year and $57 \%$ on the second year; as for Child Pugh grade C, there was a $45 \%$ chance of survival after one year and $35 \%$ on the following year.

Female with HE correspond to more than half of the cases, and most of them had an H-R score of 2. In general, H-R score in every subgroup showed female preponderance, with the exception of H-R 0 and H-R 4 (Table 4).

\begin{tabular}{|c|c|c|c|c|}
\hline & \multicolumn{3}{|c|}{ Child-Pugh score } & \multirow[t]{2}{*}{ Total } \\
\hline & A & B & C & \\
\hline $\mathrm{H}-\mathrm{R} \mathrm{O}$ & $0 \%$ & $10 \%$ & $0 \%$ & $6 \%$ \\
\hline H-R 1 & $67 \%$ & $24 \%$ & $8 \%$ & $22 \%$ \\
\hline $\mathrm{H}-\mathrm{R} 2$ & $33 \%$ & $43 \%$ & $75 \%$ & $53 \%$ \\
\hline $\mathrm{H}-\mathrm{R} 3$ & $0 \%$ & $14 \%$ & $0 \%$ & $8 \%$ \\
\hline $\mathrm{H}-\mathrm{R} 4$ & $0 \%$ & $10 \%$ & $17 \%$ & $11 \%$ \\
\hline Total & $38.3 \%$ & $58.3 \%$ & $33.4 \%$ & - \\
\hline
\end{tabular}

H-R: Halstead-Reitan.

\begin{tabular}{llllll}
\hline \multicolumn{6}{c}{ Table 4: Halstead-Reitan score with regards to gender } \\
\hline & H-R 0 & H-R 1 & H-R 2 & H-R 3 & H-R 4 \\
\hline H-R & $6 \%$ & $22 \%$ & $53 \%$ & $8 \%$ & $11 \%$ \\
Female & $6 \%$ & $8 \%$ & $33 \%$ & $6 \%$ & $6 \%$ \\
Male & $0 \%$ & $14 \%$ & $19 \%$ & $3 \%$ & $5 \%$ \\
\hline
\end{tabular}

H-R: Halstead-Reitan.

\section{DISCUSSION}

Researcher suggested that the general mean age was lower in HE cases having other etiological factors, compared to those associated with hepatitis $\mathrm{C}^{\left[{ }^{[19-21]}\right.}$ Moreover, the conjoint presence of $\mathrm{HCV}$ and alcohol catalyzed the appearance of $\mathrm{HE}$ among patients of younger age. ${ }^{[12,22]}$ The result reported $\mathrm{M} / \mathrm{F}$ ratio of $2.85 / 1$, a conclusion different from other research studies on HEs.${ }^{[13,23]}$ In addition, the etiological repartition of HE displayed contrary results to another article from China, which revealed that infection was the most common etiological reason with $40.2 \%$ of precipitation; while other researchers from Nigeria showed infection as responsible in $20.9 \%$ of cases. $^{[14,24,25}$ Furthermore, this study had a slight similar detection frequency of $\mathrm{HBV}$ when compared with the results of another research that established a proportion of $10 \% \cdot{ }^{[19,21]}$

The study highlighted through the evaluation of BMI regarding encephalopathy the part played by the high index of body muscular mass as a protective factor against $\mathrm{HE}$ development, contrary to adipose mass (Figure 1). ${ }^{[2-28]}$ Moreover, the analyzed data revealed that patients with low and normal BMI had high probability of developing $\mathrm{HE}$ as a complication of liver cirrhosis, compared to overweight patients who were less likely to develop the syndrome. ${ }^{[29-32]}$

Furthermore, HE cases developed concomitant infections such as bacterial peritonitis, chest infection, gastroenteritis, and urinary tract infection, but in few cases, concomitant infection was absent. ${ }^{[33-35]}$ The presence of concomitant infections could be explained because of the bacterial translocation and higher spontaneous neutrophil respiratory burst. ${ }^{[36]}$ Hence, neutrophil impairment is an aggravating risk factor that increases mortality among patients with HE. ${ }^{[37,38]}$ The study showed that among our samples, having simultaneous infections, inflammations or/and coagulopathy during the HE course were predominant in female patients when compared to male patients, who were rarely affected. ${ }^{[39-41]} \mathrm{HE}$ occurred in cirrhotic patients who had a severe increase in the bilirubin level during a prolong period of time. ${ }^{[42,43]}$ The De Ritis ratio (AST/ALT) can be used to indicate the level of severity and the future prognosis of $\mathrm{HE}$, as its scores give us a view of disease advancement. ${ }^{[4,13]}$

The results of the correlation analysis between H-R and Child-Pugh score reflected the cognition state and intellectual abilities of patients with HE. ${ }^{[45-47]}$ This results revealed the severity of the impairment and particularly the degree of neuromuscular inability of patients: thinking difficulties, problems with speaking fluently, guiding movements, memory alteration, and the appearance of tremors in their distal extremities. ${ }^{[4,6,48-51]}$ In addition, $\mathrm{H}-\mathrm{R}$ score with regards to genders showed that female patients in the study group were more psychologically and neurologically affected by $\mathrm{HE}$ when compared with male..$^{[4,52,53]}$

Physicians first concern, while diagnosing or treating this pathology, should be the stabilization bilirubin level and 
others laboratory values to normal, because bilirubin degradation appears to be contributing to the formation of ammonia and indirectly to the formation of $\mathrm{HE}$ syndrome. ${ }^{[42,54]}$

\section{CONCLUSION}

In summary, the study was able to find concomitant prevalence of $\mathrm{HE}$ and the high level of incidence of infection, inflammation, and coagulopathy among patients. ${ }^{[39-41]}$ Moreover, within the ward, the prevalence of liver cirrhosis was complicated by the etiology of $\mathrm{HE}$ such as alcohol, HCV and HBV. ${ }^{[19-21]}$ Hence, alcohol was identified, typically in male patients, as the main cause of hepatitis leading to liver cirrhosis and thereby to HE. It was followed by hepatitis $C$, which was spread apparently due to improper sterilization of surgical tools or unprotected sexual contact. In addition, patients suffering from both HCV and alcoholism develop a more severe form of HE within a shorter period of time. Researcher noticed that female patients were more susceptible of developing severe neuromuscular form of alteration compared to male patients. Unfortunately, we were not able to determine the precise reason yet. The patient distribution according to H-R score with regards to Child-Pugh grade showed the predominance of Grades B and C indicating poor prognosis; while H-R score with regards genders showed that mainly female were affected by neuropsychological disabilities. Patients in menopausal age already suffering from alcoholism were more likely to develop a coagulopathy (anemia) because of the development of $\mathrm{HE}$ and this helped in determining the severity and outcomes of the disease. ${ }^{[55-57]}$ In addition, the presence of infection and coagulopathy (anemia) was observed in most cases of HE. Moreover, both were the most frequent reasons for hospitalization of patients.

\section{Financial disclosure}

No financial support was received in relation to this study or article.

\section{Conflicts of interest}

The author declares that there is no conflict of interest.

\section{REFERENCES}

1. Ferenci P, Lockwood A, Mullen K, Tarter R, Weissenborn K, Blei AT. Hepatic encephalopathy--definition, nomenclature, diagnosis, and quantification: final report of the working party at the 11th World Congresses of Gastroenterology, Vienna, 1998. Hepatology 2002, 35: 716-21.

2. American Association for the Study of Liver Diseases; European Association for the Study of the Liver. Hepatic encephalopathy in chronic liver disease: 2014 practice guideline by the European Association for the Study of the Liver and the American Association for the Study of Liver Diseases. J Hepatol 2014; 61: 642-59.

3. Lizardi-Cervera J, Almeda P, Guevara L, Uribe M. Hepatic encephalopathy: a review. Ann Hepatol 2003; 2:122-30.

4. Bajaj JS, Hafeezullah M, Franco J, Varma RR, Hoffmann RG, Knox JF, et al. Inhibitory control test for the diagnosis of minimal hepatic encephalopathy. Gastroenterology, 2008, 135, 1591-600.e1.

5. Liu Q, Duan ZP, Ha DK, Bengmark S, Kurtovic J, Riordan SM. Synbiotic modulation of gut flora: effect on minimal hepatic encephalopathy in patients with cirrhosis. Hepatology 2004; 39: 1441-9.

6. Córdoba J, Cabrera J, Lataif L, Penev P, Zee P, Blei AT. High prevalence of sleep disturbance in cirrhosis. Hepatology 1998; 27, 339-45.

7. Häussinger D, Kircheis G. Hepatic encephalopathy. Praxis (Bern. 1994) 2002; 91: 957-63.

8. Li T, Li X, Zhou W, Cui X, Ma L. Dynamic susceptibility contrastenhanced first-pass perfusion MR imaging in patients with subclinical hepatic encephalopathy. J Neuroradiol 2012; 39: 290-4.

9. Pugh RN, Murray-Lyon IM, Dawson JL, Pietroni MC, Williams R. Transection of the oesophagus for bleeding oesophageal varices. $\mathrm{Br} \mathrm{J}$ Surg 1973; 60: 646-9.

10. Amodio P, Del Piccolo F, Marchetti P, Angeli P, Iemmolo R, Caregaro L, et al. Clinical features and survival of cirrhotic patients with subclinical cognitive alterations detected by the number connection test and computerized psychometric tests. Hepatology 1999; 29: 1662-7.

11. Pawlotsky JM. Molecular diagnosis of viral hepatitis. Gastroenterology 2002; 122: 1554-68.

12. Mutlu G, Kumdali A. A comparative study to detect the HBsAg by the ELISA, RIA and PHA technics in patients with viral hepatitis. Mikrobiyol Bul 1984; 18: 190-8.

13. Botros M, Sikaris KA. The de ritis ratio: the test of time. Clin Biochem Rev 2013; 34: 117-30.

14. Kamath PS, Wiesner RH, Malinchoc M, Kremers W, Therneau TM, Kosberg CL, et al. A model to predict survival in patients with end-stage liver disease. Hepatology 2001; 33: 464-70

15. Tripodi A, Chantarangkul V, Primignani M, Fabris F, Dell'Era A, Sei C, et al. The international normalized ratio calibrated for cirrhosis (INR(liver)) normalizes prothrombin time results for model for end-stage liver disease calculation. Hepatology 2007; 46: 520-7.

16. Schomerus $\mathrm{H}, \mathrm{Hamster} W$. Neuropsychological aspects of portal-systemic encephalopathy. Metab Brain Dis 1998; 13: 361-77.

17. Bryman A \&Cramer D, Quantitative Data Analysis with SPSS for Windows. Routledge, London 1997. ISBN: 978-0-415-57918-6 (hbk)

18. World Medical Association. World Medical Association Declaration of Helsinki. Ethical principles for medical research involving human subjects. Bull World Health Organ 2001;79:373-4.

19. Maqsood S, Saleem A, Iqbal A, Butt JA. Precipitating factors of hepatic encephalopathy: experience at Pakistan Institute of Medical Sciences Islamabad. J Ayub Med Coll Abbottabad 2006; 18: 58-62.

20. Rohra DK, Jaipal, Khowaja AA, Mahmood K, Ahuja KL. Precipitating factors of hepatic encephalopathy in patients with chronic liver disease at civil hospital Karachi. J Coll Physicians Surg Pak 2008;18: 130-1.

21. Zakaria M, BUTT MA, Syed Rizwan Hussain, Farid Rana. Hepatic encephalopathy: Precipitating factors in patients with cirrhosis. Professional Med J 2008; 15:375-9.

22. Mokdad AA, Lopez AD, Shahraz S, Lozano R, Mokdad AH, Stanaway J, et al. Liver cirrhosis mortality in 187 countries between 1980 and 2010: a systematic analysis. BMC Med 2014; 12: 145.

23. Hayat A, Shaikh N, Memon F. Identification of precipitating factors in hepatic encephalopathy patients at Liaquat University Hospital Jamshoro. World Appl Sci J 2010; 08: 661-6.

24. Wang QM, Ji Q, Duan ZJ, Zhang M, Chang QY. A study on the position and etiology of infection in cirrhotic patients: A potential precipitating factor contributing to hepatic encephalopathy. Exp Ther Med, 2013, 6: 584-90. 
25. Onyekwere CA, Ogbera AO, Hameed L. Chronic liver disease and hepatic encephalopathy: clinical profile and outcomes. Niger J Clin Pract 2001, 14: 181-5.

26. Larson AM, Polson J, Fontana RJ, Davern TJ, Lalani E, Hynan LS, et al. Acetaminophen-induced acute liver failure: results of a United States multicenter, prospective study. Hepatology 2005, 42: 1364-72.

27. Holstein A, Hinze S, Thießen E, Plaschke A, Egberts EH. Clinical implications of hepatogenous diabetes in liver cirrhosis. J Gastroenterol Hepatol 2002; 17: 677-81.

28. Khamaysi I, William N, Olga A, Alex I, Vladimir M, Kamal D, et al. Subclinical hepatic encephalopathy in cirrhotic patients is not aggravated by sedation with propofol compared to midazolam: A randomized controlled study. J Hepatol 2011, 54: 72-7.

29. Hui JM, Kench JG, Chitturi S, Sud A, Farrell GC, Byth K, et al. Longterm outcomes of cirrhosis in nonalcoholic steatohepatitis compared with hepatitis C. Hepatology 2003; 38: 420-7.

30. Angulo P, Hui JM, Marchesini G, Bugianesi E, George J, Farrell GC, et al. The NAFLD fibrosis score: A noninvasive system that identifies liver fibrosis in patients with NAFLD. Hepatology 2007; 45: 846-54.

31. Argo CK, Caldwell SH. Epidemiology and natural history of nonalcoholic steatohepatitis. Clin Liver Dis 2009; 13: 511-31.

32. Berzigotti A, Garcia-Tsao G, Bosch J, Grace ND, Burroughs AK, Morillas $\mathrm{R}$, et al. Obesity is an independent risk factor for clinical decompensation in patients with cirrhosis. Hepatology 2011; 54: 555-61.

33. Leber B, Spindelboeck W, Stadlbauer V. Infectious complications of acute and chronic liver disease. Semin Respir Crit Care Med 2012; 33: 80-95.

34. Pleguezuelo M, Benitez JM, Jurado J, Montero JL, De la Mata M. Diagnosis and management of bacterial infections in decompensated cirrhosis. World J. Hepatol 2013; 5: 16-25.

35. Merli M, Lucidi C, Giannelli V, Giusto M, Riggio O, Falcone M, et al. Cirrhotic patients are at risk for health care-associated bacterial infections. Clin. Gastroenterol Hepatol 2010; 8: 979-85.

36. Shawcross DL, Wright GA, Stadlbauer V, Hodges SJ, Davies NA, WheelerJones $C$, et al. Ammonia impairs neutrophil phagocytic function in liver disease. Hepatology 2008; 48: 1202-12.

37. Tritto G, Bechlis Z, Stadlbauer V, Davies N, Francés R, Shah N, et al. Evidence of neutrophil functional defect despite inflammation in stable cirrhosis. J Hepatol 2011; 55: 574-81.

38. Mookerjee RP, Stadlbauer V, Lidder S, Wright GA, Hodges SJ, Davies NA, et al. Neutrophil dysfunction in alcoholic hepatitis superimposed on cirrhosis is reversible and predicts the outcome. Hepatology 2007; 46: 831-40.

39. Taneja SK, Dhiman RK. Prevention and management of bacterial infections in cirrhosis. Int J Hepatol 2011; 2001: 784540.

40. McCullough AJ. Alcoholic Liver Disease: Introduction. Am J Gastroenterol 2010; 105: 14-32.

41. Guevara M, Baccaro ME, Ríos J, Martín-Llahí M, Uriz J, Ruiz del Arbol $\mathrm{L}$, et al. Risk factors for hepatic encephalopathy in patients with cirrhosis and refractory ascites: relevance of serum sodium concentration. Liver Int 2010; 30: 1137-42.

42. Ong JP, Aggarwal A, Krieger D, Easley KA, Karafa MT, Van Lente F, et al. Correlation between ammonia levels and the severity of hepatic encephalopathy. Am J Med 2003; 114: 188-93.
43. Rahbari NN, Garden OJ, Padbury R, Brooke-Smith M, Crawford M, Adam R, et al. Posthepatectomy liver failure: A definition and grading by the International Study Group of Liver Surgery (ISGLS). Surgery 2011; 149: 713-24.

44. Bezan A, Mrsic E, Krieger D, Stojakovic T, Pummer K, Zigeuner R, et al. The Preoperative AST/ALT (De Ritis) Ratio Represents a Poor Prognostic Factor in a Cohort of Patients with Nonmetastatic Renal Cell Carcinoma. J Urol 2015; 194: 30-5.

45. Malaguarnera M, Gargante MP, Cristaldi E, Vacante M, Risino C, Cammalleri L, et al. Acetyl-L-carnitine treatment in minimal hepatic encephalopathy. Dig Dis Sci 2008; 53: 3018-25.

46. Cecere A, Ciaramella F, Tancredi L, Romano C, Gattoni A. Efficacy of $\mathrm{L}$-carnitine in reducing hyperammonaemia and improving neuropsychological test performance in patients with hepatic cirrhosis: results of a randomised trial. Clin Drug Investig 2002; 22: 7-14.

47. Dhiman RK, Kurmi R, Thumburu KK, Venkataramarao SH, Agarwal R, Duseja A, et al. Diagnosis and prognostic significance of minimal hepatic encephalopathy in patients with cirrhosis of liver. Dig Dis Sci 2010; 55 : 2381-90.

48. Foster KJ, Lin S, Turck CJ. Current and emerging strategies for treating hepatic encephalopathy. Crit Care Nurs Clin North Am 2010; 22: 341-50.

49. Bismuth M, Funakoshi N, Cadranel JF, Blanc P. Hepatic encephalopathy: from pathophysiology to therapeutic management. Eur J Gastroenterol Hepatol 2011; 23: 8-22.

50. Askgaard G, Grønbæk M, Kjær MS, Tjønneland A, Tolstrup JS. Alcohol drinking pattern and risk of alcoholic liver cirrhosis: A prospective cohort study. J Hepatol 2015; 62: 1061-7.

51. Shah A, Amarapurkar D, Dharod M, Chandnani M, Baijal R, Kumar P, et al. Coagulopathy in cirrhosis: A prospective study to correlate conventional tests of coagulation and bleeding following invasive procedures in cirrhotics. Indian J Gastroenterol 2015; 34: 359-64.

52. Duseja A, Chawla YK, Dhiman RK, Kumar A, Choudhary N, Taneja S. Non-hepatic insults are common acute precipitants in patients with acute on chronic liver failure (ACLF). Dig Dis Sci 2010; 55: 3188-92.

53. Johnson-Greene D, Adams KM, Gilman S, Junck L. Relationship between neuropsychological and emotional functioning in severe chronic alcoholism. Clin Neuropsychol, 2002; 16: 300-9.

54. Lockwood AH. Blood ammonia levels and hepatic encephalopathy. Metab Brain Dis 2004; 19: 345-9.

55. Farrell GC, Larter CZ. Nonalcoholic fatty liver disease: from steatosis to cirrhosis. Hepatology 2006; 43: S99-112.

56. Panagaria N, Varma K, Nijhawan S, Mathur A, Rai RR. Quality of life and nutritional status in alcohol addicts and patients with chronic liver disease. Trop. Gastroenterol 2007; 28: 171-5.

57. Zatoński WA, Sulkowska U, Mańczuk M, Rehm J, Boffetta P, Lowenfels $\mathrm{AB}$, et al. Liver cirrhosis mortality in Europe, with special attention to Central and Eastern Europe. Eur Addict Res 2010; 16: 193-201.

How to cite this article: Djiambou-Nganjeu $\mathrm{H}$. Hepatic encephalopathy in patients in Lviv (Ukraine). J Transl Intern Med 2018; 6: 146-51. 